\title{
MICROTENSILE BOND STRENGTH AND NANOLEACKAGE OF DENTIN SURFACES PRETREATED WITH DIFFERENT ETCHING MATERIALS
}

\author{
Ahmed Adel A. Aziz* and Heba Fathy El Imam**
}

\begin{abstract}
This in-vitro study aimed to evaluate microtensile bond strength and nanoleackage of dentin surfaces pretreated with different etching materials. Twenty four extracted human intact second molar were selected and debrided to remove remnants of periodontal ligaments. Occlusal surfaces were flattened to expose a flat area of dentin under copious water coolant. One dentin bonding system (Te-Econom Bond) and one dental resin composite restoration (Tetric N-Ceram) were used for the study. The teeth were divided into four groups (6 each) according to the type of etchant material used as follows: group A - citric acid 6\%, group B - citric acid 10\%, group C - citric acid 20\%, and group D- phosphoric acid 37\%. The etchants were applied for 15 seconds to the dentin surface. After which teeth were washed, dried, then bonding agent was applied followed by the resin composite restoration. Then a longitudinal sectioning of restored teeth was made to obtain composite-dentin beams of $(0.9 \times 0.9 \mathrm{~mm})$ in area. Each beam was composed of composite and dentin with adhesive at the interface. The microtensile bond strength ( $\mu$ TBS) was measured and the nanoleakage was observed using SEM. Data was then recorded, tabulated and statistically analyzed. There was no statistical significant difference between the results of the $\mu$ TBS of groups

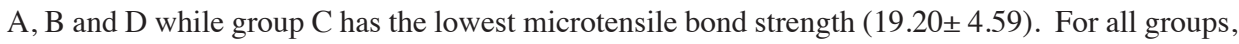
nanoleackage was more demonstrated at group $\mathrm{C}$ and $\mathrm{D}$, while group $\mathrm{B}$ show mild nanoleackage and no nanoleackage was observed for group A. It was concluded that low concentrations of citric acid was effective as etchant material compared to phosphoric acid on dentin surface in terms of microtensile bond strength and nanoleakage.
\end{abstract}

\section{INTRODUCTION}

Dentin is a vital hydrated composite tissue with variable morphology that varies with location. The peritubular dentin is mostly of apatite and lines the lumen of the tubule and consists mainly of two distinct materials: collagen matrix and appetite crystal reinforcement. In bonding techniques, the permeability of dentin to adhesive agents is a critical point. Subsequently, there have been many existing researches for resin infiltration to both dentinal tubules and intertubular dentin which in

* Lecturer of Conservative Dentistry, Faculty of Dentistry, Badr University in Cairo (BUC), Cairo, Egypt.

** Lecturer of Oral Histology , Faculty of Dentistry, Egyptian Russian University, Cairo, Egypt. 
turn enhanced the bond strength ${ }^{[1]}$. However, acid conditioning was the only way to remove apatite of dentin and hence resin infiltration occurred into intertubular dentin ${ }^{[2]}$.

The tooth surface to which the bond has to occur is mostly covered with a loosely bonded smear layer with thickness between 0.05 and $15 \mu \mathrm{m}$ after cavity preparation. It is composed of shattered and crushed hydroxyapatite, along with denatured and fragmented collagen. Bacteria and saliva may be found as contaminants within smear layer in vivo. This smear layer affect the bonding surface negatively as it reduces the bond to the underlying dentin. Thus, to eliminate the effect of smear layer and promote bonding, different surface treatment agents have been proposed to remove or modify the smear layer before placing the restoration ${ }^{[3]}$.

A moderate to severe pulpal reactions can be resulted from acid etching but it was found that these reactions are highly caused by microleakage of the bacteria and their byproducts ${ }^{[4]}$. To enhance the adhesion in preventive and restorative dentistry, etching to dentin was used as it was considered as a surface preparation step to remove any surface debris after tooth cutting. Furthermore, acid etching has been reported to reduce microleakage around restoration margins and provide cuspal reinforcement ${ }^{[3]}$.

Various commercially used acidic materials in the dental adhesive systems were applied to etch both enamel and dentin. These acidic materials are used to eliminate or remove the smear layer from the cut dentin surface and cause dentin demineralization to a certain depth besides leaving behind a network rich of collagen in order to interact with the adhesive resin and finally a hybrid layer formation was obtained ${ }^{[6]}$. Different acid etchants have been used for removing the smear layer and demineralizing the dentin surface. Thus, it allows for penetration of bonding resins and formation of tags ${ }^{[7]}$.

Total etch adhesive system is a technique in which the full etching of dental substrate by phosphoric acid is first done followed by the application of both primer and bond, which can be presented in a single or in separate bottles. The self-etching systems were relevant and used nowadays as they have several advantages over the total etch techniques from which are its simplicity, convenience and time saving because no etching step is required ${ }^{[8]}$. The application of phosphoric acid creates a pattern with more retentive areas in enamel. Some researches advocated the use of total etch techniques in case of making indirect restorations or when large areas of enamel were present. Also it has been proved that the application of $37 \%$ phosphoric acid to dentin in some cases may have resulted in excessive demineralization and so there is improper resin infiltration in the collagen fibers which in turn resulted in poor adhesion ${ }^{[9]}$.

Citric acid is a weak organic acid that has different functions as natural preservative substance, cleansing material and antioxidant used to add sour taste in food and soft drinks, found in fruit especially citrus and vegetable. Citric acid affects the dentin by causing permanently demineralized dentin surface by erasing or the removal of smear layer and the most superficial dentin and opening of the dentin tubules and exposing the collagen. It can be very erosive due to the capability to bind metal ion. The influence of citric acid was observed if it contacts the enamel or dentin surfaces. Enamel surface which is etched by citric acid will be erosive. It was found that when using excessive amount or high concentrations of citric acid on enamel and dentin surfaces can result in highly erosive demineralization and hence affect the adhesion ${ }^{[10]}$.

Microtensile bond strength has always been used to evaluate the bond strength of the dentin adhesive restorations ${ }^{[11]}$. Also, Scanning Electron Microscopy (SEM) has been used traditionally as a method of assessment for the presence of nanoleakage as it demonstrated the different layers the dentin-adhesive-resin joint ${ }^{[12]}$.

Therefore, the aim of the present study was to 
evaluate microtensile bond strength and nanoleackage of dentin surfaces pretreated with different concentrations of citric acid compared to $37 \%$ phosphoric acid.

\section{MATERIALS AND METHODS}

Different materials used in this study including the composition and manufacturer of each material are presented in Table 1:

- Etching materials: citric acid 6\%, citric acid $10 \%$, citric acid $20 \%$ and phosphoric acid $37 \%$.

- Bonding agent: Te-Econom Bond

- Light-curing, radiopaque nano-hybrid composite resin restoration: Tetric $\mathrm{N}-\mathrm{Ceram}$

- $\quad$ Light curing unit: Bluephase N MC LED

For the preparation of citric acid etching solutions, a 100ml pipette was filled with distilled water then, using a sensitive digital scale:

- 6 gm of citric acid powder were weighted and added to the $100 \mathrm{ml}$ distilled water to prepare the citric acid $6 \%$.

- $10 \mathrm{gm}$ of citric acid powder were weighted and added to the $100 \mathrm{ml}$ distilled water to prepare the citric acid $10 \%$.

- 20 gm of citric acid powder were weighted and added to the $100 \mathrm{ml}$ distilled water to prepare the citric acid $20 \%$.

After that the solution was shacked well to make sure that the citric acid powder has completely dissolved in the distilled water.

A total of twenty four freshly extracted human intact second molars were selected for this study. They were debrided to remove remnants of periodontal ligaments. The teeth were stored in normal saline at room temperature till use.

The selected teeth were divided into four groups (6 each) according to different etchant acid used as follows: Group A - citric acid 6\%, Group B - citric acid 10\%, Group C - citric acid 20\%, and Group D- phosphoric acid 37\%. Occlusal surfaces were flattened to the level of the dentino-enamel junction using microtome to expose a flat area of dentin under copious water coolant. Different etching acids were applied for 15 seconds to the dentin surface with different applicator tips for each new sample. The surfaces were washed with water and air dried. Then, bonding agent was applied using Te-Econom Bond and light cured using bluephase N MC LED light curing unit for 20 seconds. The reduced occlusal surface was built with $3 \mathrm{~mm}$ layer by layer using Tetric $\mathrm{N}$-Ceram resin composite restoration and light cured to facilitate longitudinal sectioning of the restored teeth. For easily distinguishing between different acids used, color coding was done for each group by applying permanent ink on the occlusal surfaces of the restored teeth as follows: red for citric acid $6 \%$, green for citric acid $10 \%$, black for citric acid $20 \%$ and blue for phosphoric acid $37 \%$. The restored teeth were kept at $37^{\circ} \mathrm{C}$ with relative humidity for 24 hours in an incubator.

\section{Microtensile bond strength test}

Sixteen teeth were used for the microtensile bond strength test, each four representing each of the four groups. Cylindrical Teflon mold (15-mm diameter and 40-mm height), with a corresponding metal ring with two opposing screws at its top was used to produce acrylic resin blocks. The screws were used to hold the tooth in place in a centralized position, parallel to the long axis of the mold, during the setting of acrylic resin. Teeth fixed in acrylic resin blocks were then mounted in an automated diamond saw.

Then longitudinal sectioning of restored teeth was made to obtain composite-dentin beams of ( 0.9 $\mathrm{mm} \times 0.9 \mathrm{~mm}$ ). Each beam was composed of composite and dentin with adhesive at the interface. Ten beams were collected from each tooth.

For the longitudinal sectioning to be perpendicular to the flat occlusal surface of restored teeth, 
a specially designed gripping attachment was used to hold acrylic blocks with mounted teeth firm in place, parallel to the sectioning direction, thus maintaining the perpendicular relation between the cutting disc and the occlusal surface. After mounting in the gripping attachment, restored teeth were serially sectioned, using a $0.3-\mathrm{mm}$ thick diamond coated disc, at $2050 \mathrm{rpm} ; 8.8 \mathrm{~mm} / \mathrm{min}$ feeding rate; under copious coolant.

A digital caliper was used to check the thickness and length of all beams. Resultant beams were $0.9 \pm 0.1 \mathrm{~mm}$ in thickness and $5.5 \pm 1 \mathrm{~mm}$ in length. Each beam was stored in distilled water at room temperature in a tight-seal plastic cone.

After that the beams were mounted onto the universal testing machine and tensile load was applied, at a cross-head speed of $0.5 \mathrm{~mm} / \mathrm{min}$, until bonding failure of the specimen occurred. Bond strength was calculated using MegaPascal (Bluehill Lite software, Instron, MA, USA).

\section{Nanoleakage Analysis}

Eight teeth were used for the nanoleakage analysis, each two representing each of the four groups. Four slabs were collected from each tooth. Slabs were, then, immersed in a solution of ammoniacal silver nitrate for 24 hours, washed in distilled water, immersed in light developer for 8 hours and then embedded in polystyrene resin. Embedded samples were polished with silicon carbide paper. Samples were demineralized and deproteinated with $85 \%$ phosphoric acid and $2 \%$ hypochlorite. Samples were dehydrated in serial ethanol solutions. The side of dentin sticks was analyzed by Scanning Electron Microscope.

For each tooth, two slabs were selected and analyzed for silver nitrate infiltration to detect nanoleakage that appeared as silver nitrate deposits along the base of the hybrid layer of composite resin under different acid- etching. Six images were taken for each slab by Scanning Electron Microscope.

TABLE (1) Material specifications, manufacturers and compositions

\begin{tabular}{|c|c|c|c|}
\hline Material & Manufacturer & Batch No. & Descriptions/ Compositions \\
\hline $\begin{array}{l}\text { Citric acid } \\
\text { @RECTAPUR }\end{array}$ & PR Chemicals & $77-92-9$ & $\begin{array}{l}\text { Crystallized citric Acid } \\
\mathrm{C}_{6} \mathrm{H}_{8} \mathrm{O}_{7}, \mathrm{H}_{2} \mathrm{O}: 99 \%\end{array}$ \\
\hline Meta Etchant & $\begin{array}{l}\text { Meta Biomed Co. Ltd., Cheongju-si, } \\
\text { Chungbuk, Korea } \\
\text { http://www.meta-biomed.com/ }\end{array}$ & MET1704271 & $37 \%$ Phosphoric acid semi gel \\
\hline Te-Econom Bond & $\begin{array}{l}\text { Ivoclar Vivadent AG, Liechtenstein, } \\
\text { Switzerland } \\
\text { http://www.ivoclarvivadent.com/ }\end{array}$ & X36936 & $\begin{array}{l}\text { HEMA, di- and monomethacrylates, inorganic } \\
\text { fillers, initiators and stabilizers in an alcohol } \\
\text { solution. }\end{array}$ \\
\hline Tetric N-Ceram & $\begin{array}{l}\text { Ivoclar Vivadent AG, Liechtenstein, } \\
\text { Switzerland } \\
\underline{\text { http://www.ivoclarvivadent.com/ }}\end{array}$ & X34651 & $\begin{array}{l}\text { Urethane dimethacrylate, Bis-GMA }(15 \%) \text {, } \\
\text { Ethoxylated Bis-EMA }(3.8 \%) \text {, Barium } \\
\text { glass, ytterbium trifluoride, mixed oxide, } \\
\text { silicon dioxide ( } 63.5 \%) \text {, Prepolymers }(17 \%) \text {, } \\
\text { Additives, stabilizers, catalysts, pigments } \\
(0.7 \%)\end{array}$ \\
\hline $\begin{array}{l}\text { Bluephase N MC } \\
\text { LED Light cur- } \\
\text { ing unit }\end{array}$ & $\begin{array}{l}\text { Ivoclar Vivadent AG, Liechtenstein, } \\
\text { Switzerland } \\
\text { http://www.ivoclarvivadent.com/ }\end{array}$ & - & Light intensity $=800 \mathrm{~mW} / \mathrm{cm}^{2}$ \\
\hline
\end{tabular}


Data was then recorded, tabulated and statistically analyzed. Data was analyzed using Statistical Package for Social Science software computer program version 22 (SPSS, Inc., Chicago, IL, USA). Data were presented in mean and standard deviation. One way Analysis of variance (ANOVA) and tukey were used for pair-wise comparison between the groups. P-value less than 0.05 was considered statistically significant.

\section{RESULTS}

This study was carried out to evaluate microtensile bond strength and nanoleackage of dentin surfaces pretreated with different etching materials.

\section{Microtensile test results}

Table (2) and Figure (1) show mean and standard deviation of the microtensile bond strength ( $\mu \mathrm{TBS}$ ) values (in $\mathrm{MPa}$ ) of the different acid etching materials used as independent variable according to one way ANOVA followed by post-hoc Tukey test that was applied for the interaction and comparing among different variables. According to one way ANOVA test, there was statistically significant difference among all groups at $\mathrm{P}$-value $=0.03$. Posthoc Tukey test found that there was statistically significant difference of $\mu$ TBS between group A (citric acid 6\%) and group C (citric acid 20\%) at p-value 0.048 . The highest microtensile bond strength has been found in citric acid 6\% group
A (27.62 \pm 7.62$)$ and the lowest microtensile bond strength results among citric acid 20\% group C $(19.20 \pm 4.59)$. There was no statistical significant results $\mu$ TBS between acid etching among group C (citric acid 20\%), group D (phosphoric acid $37 \%$ ) and group B (citric acid 10\%). There was no statistically significant difference of microtensile bond strength $37 \%$ phosphate acid between different citric acid concentrations. Low concentrations of citric acid (6\% and 10\%) applied on dentin surface for 15 seconds were effective as etchant compared to phosphoric acid on microtensile bond strength and for opening maximum number of dentinal tubules. While, excessive concentration of citric acid $20 \%$ negatively affected microtensile bond strength to dentin substrate.

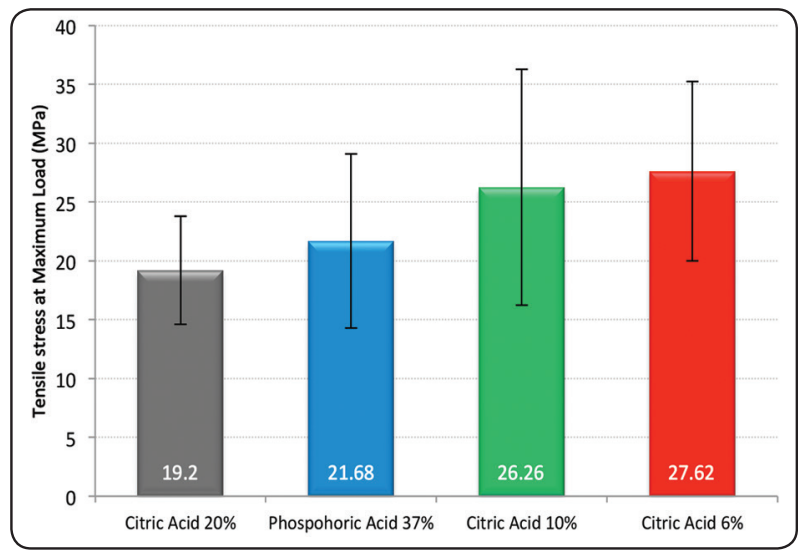

Fig. (1): Bar chart showing tensile stress at maximum load for all groups

TABLE (2) Comparison among mean and standard deviation (SD) of different groups according to Tensile stress at Maximum Load (MPa)

\begin{tabular}{|l|c|c|c|c|c|}
\hline & $\begin{array}{c}\text { Citric Acid 20\% } \\
\text { Group }\end{array}$ & $\begin{array}{c}\text { Phospohoric Acid } \\
\text { 37\% Group }\end{array}$ & $\begin{array}{c}\text { Citric Acid 10\% } \\
\text { Group }\end{array}$ & Citric Acid 6\% Group & P \\
\hline Maximum Load (MPa) & $19.20 \pm 4.59$ & $21.68 \pm 7.39$ & $26.26 \pm 10.04$ & $27.62 \pm 7.62$ & $0.03 *$ \\
\hline P1 & & 0.85 & 0.12 & $0.048^{*}$ & \\
\hline P2 & & & 0.46 & 0.24 & \\
\hline P3 & & & & 0.97 & \\
\hline
\end{tabular}

P: Probability *:significance $<0.05$

P1: significance relative to Citric Acid $20 \%$ Group

P2: significance relative to Phospohoric Acid 37\% Group

P3: significance relative to Citric Acid 10\% Group 


\section{Nanoleakage results}

Figure (2) show the scanning electron microscope photomicrograph of composite- adhesivedentin interface of all groups for:

- Fig. (2-A): SEM photomicrograph of Group A (citric acid 6\%) revealed that the dentin surface had regular smooth area and had no silver nitrate deposits along the base of the hybrid layer between the dentin and bonding agent, indicating no nanoleakage observed.

- Fig. (2-B): SEM photomicrograph of Group B (citric acid 10\%) revealed regular smooth dentin surface with a little infiltration of silver nitrate between dentin and bonding agent.

- Fig. (2-C): SEM photomicrograph of Group C (citric acid 20\%) revealed that silver nitrate deposits had moderate infiltration along the base of the hybrid layer indicating that nanoleakage observed (Fig. 2-C).

- Fig. (2-D): SEM photomicrograph of Group D (phosphoric acid 37\%) revealed that silver nitrate deposits with moderate infiltration in the hybrid layer indicating that nanoleakage observed. Silver nitrate penetration occurs between dentin and bonding agent and within the dentinal tubules.
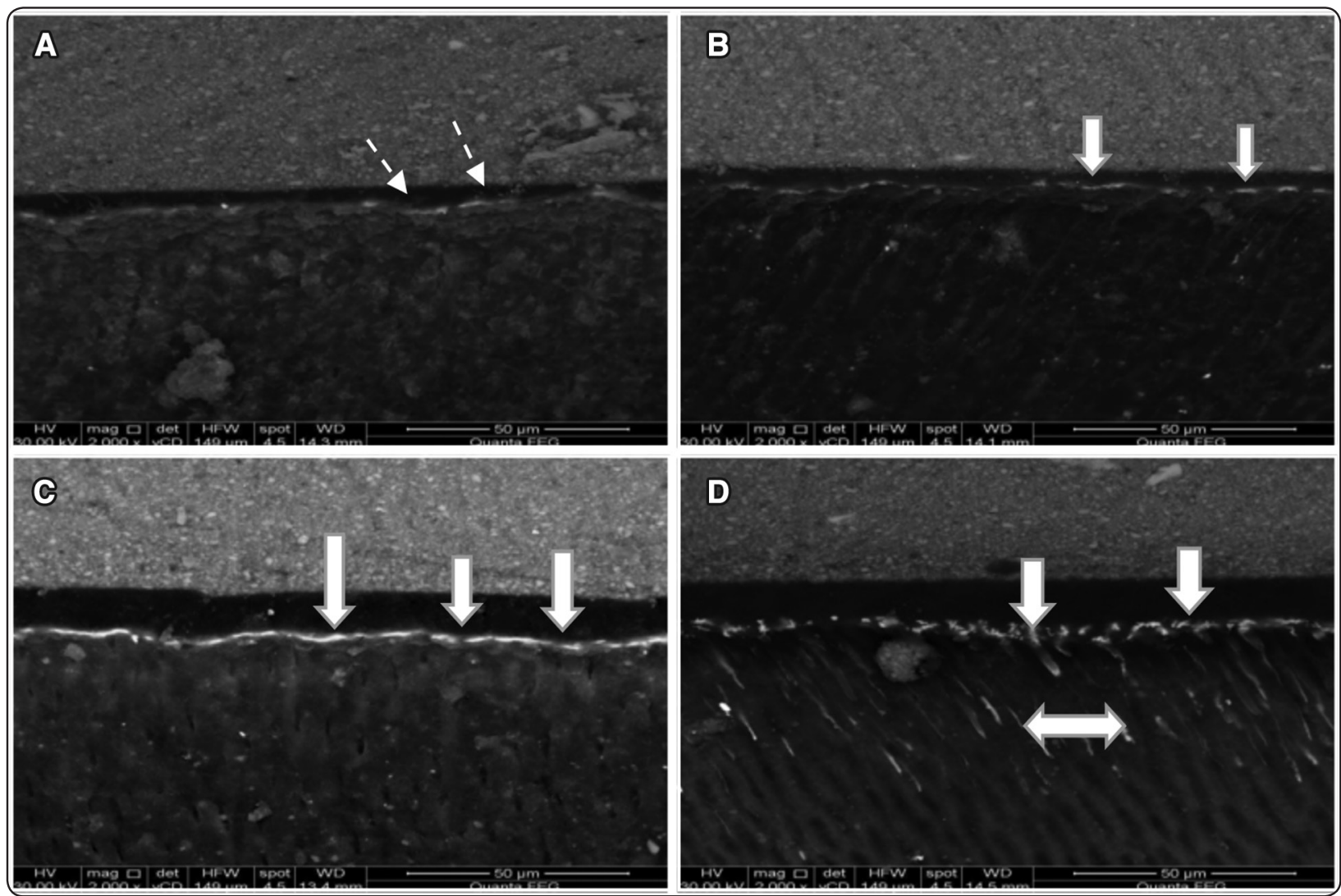

Fig. (2): SEM photomicrograph of composite- adhesive-dentin interface of all groups showing: A- Group A: no silver nitrate deposits with acid etching of citric acid 6\%. Continuous layer of hybrid layer (dashed arrow) in dentinal tubules. B- Group B: arrows show a little infiltration of silver nitrate between dentin and bonding agent with acid etching of citric acid $10 \%$. C- Group C: Nanoleakage as arrows showing the silver nitrate moderate infiltration in the hybrid layer with acid etching of citric acid 20\%. D- Group D: Nanoleakage as arrows showing the silver nitrate moderate infiltration in the hybrid layer with acid etching of phosphoric acid 37\%. Silver nitrate penetration occurs between dentin and bonding agent and within the dentinal tubules (left- right arrow) as silver nitrate uptake was very high. 
For all groups, nanoleakage more demonstrated for citric acid $20 \%$ and phosphoric acid 37\%. Low concentration of citric acid $6 \%$ has nanomechanical bond in comparison with phosphoric acid that showed some degree of nanoleakage.

\section{DISCUSSION}

This study aimed to evaluate microtensile bond strength and nanoleackage of dentin surfaces pretreated with different etching materials.

It has been taken into consideration that this was invitro study and only one bonding system total etch has been used. Numerous researches were conducted both invivo and invitro, although invivo were evident. The current study used invitro laboratory screening tests which have some advantages over clinical ones as it include patient-independence, it saves time and money, in addition to the ability to test a single variable and easy to conduct ${ }^{[13]}$.

Van Meerbeck et al. stated that bonding mechanism of different etched dentin adhesive systems were very similar in spite of the different types of conditioners, primers or adhesive resins used ${ }^{[14]}$. The acid etching has many functions from which were opening of dentinal tubules, increasing the dentin permeability, removing of the smear layer and decalcification of the peritubular and intertubular dentin ${ }^{[13]}$. The depth of the demineralizations depends upon many factors such as ph, viscocity, concentration and the time of application of the acid etch $^{[14,17]}$.

Measuring of bond strength can be evaluated by a variety of testing methods including shear, microshear and microtensile tests. In this study, microtensile bond strength ( $\mu \mathrm{TBS}$ ) was chosen as it permits the alignment of different samples in a proper way which result in a stress pattern with a homogeneous distribution also it facilitate the longitudinal sectioning of the samples and it provides better economic sample use and it can test the irregular surfaces ${ }^{[18]}$. The $\mu$ TBS of each beam was calculated as the force of failure divided by the bonded cross-sectional surface area and expressed in MPa as Zhao et al in 2006 have done ${ }^{[19]}$.

In the present study, different acids etchings was used to remove the smear layer, to expose the intertubular dentin and peritubular dentin and demineralize the superfacial dentin matrix to allow the infiltration of resin material. Furthermore, Acids etching could create voids between the collagen fibers of dentin due to loss of hydroxyl appetite crystals ${ }^{[20]}$.

The acid etching agents used at this study exposed the dentinal tubules and the collagen matrix was in accordance with Hanes et al. who also found that some amount of surface debris on specimens treated with different acids was shown ${ }^{[21]}$. And also, in accordance with the results of Van Meerbeeck et al. that showed a micromechanical bond was created - through the formation of "resin tags" of the adhesive into the dentinal tubules as well as a nano mechanical bond - through the penetration of the adhesive in the demineralized space between the collagen fibers of the intertubular dentin ${ }^{[22]}$.

In the present research, two different etching materials with different concentrations were used and this was in agreement with Eick et al. who stated that the adhesive dentine bond strength was achieved from its morphology and the etching agents used and also, was in agreement with the results of Wang and Spencer that the effect of the etching agent depends on the type and concentration of the acid, time and the methods of application ${ }^{[23,24]}$.

Citric acid was selected for the present study because it was a weak organic acid with relatively low cytotoxicity and when applied on dentin, it leads to opening of dentinal tubules, removal of the smear layer and demineralization of the dentin surface ${ }^{[25]}$.

The use of total-etch adhesive systems using phosphoric acid $37 \%$ was advocated by many researches and most commonly used commercial acid in dentistry as it causes demineralization of enamel 
and dentin and helps in resin impregnation and enhance bonding procedure ${ }^{[26]}$.

The results of the current study showed that citric acid 20\% gives low bond strength (19.20 \pm 4.59 $\mathrm{MPa}$ ) that was in accordance with Gateva et al. who stated that etching dentin with high concentration of acids can result in excessive intertubular dentin demineralization and collagen collapse, which lead to the perceptation of calcium phosphate crystals and hence protective layer will be formed which cannot be completely infiltrated by the adhesive resin ${ }^{[27]}$.

The current results were in accordance with Marshall et al. who stated that citric acid yields higher etching rates than phosphoric acid. This was due to the calcium citrate complexes formed on dentin surface beside simple dissolution ${ }^{[28]}$.

On the other hand the results of etching using citric acid $10 \%$, in this study, reveals favorable bond strength $(26.26 \pm 10.04 \mathrm{MPa})$, this was in contradiction with Nakabyashi et al. who stated that etching with $10 \%$ citric acid allowed by air drying lead to collagen collapse and resulted in the formation of bonded layers with a poor quality ${ }^{[29}$. Also some prior researches revealed that increasing the concentration of the citric acid used for etching lead to increasing the etching rate ${ }^{[30]}$.

The fact that etching with phosphoric acid $37 \%$ gives low bond strength value $(21.68 \pm 7.39 \mathrm{MPa})$ was in accordance with Drummond et al. who stated that this may affect collagen layer by facilitating its collapse, and also in accordance with Nakayashi et al. who attributed the decreased bond strength of phosphoric acid to the non-preservation of collagen bundles ${ }^{[31,29]}$. In addition to that phosphoric acid $37 \%$ creates pores within the collagen matrix at a nanoscale level when it completely demineralize the intertubular dentin ${ }^{[13]}$. While the results of the current study contradict with that of Bagmar et al. who stated that phosphoric acid 37\% opened maximum number of entinal tubules with less smear plug in comparison to citric acid 5\% ${ }^{[32]}$.
Sano et al. defined the nanoleackage as porosities found within or underneath hybrid layer and has a range lower than $50 \mathrm{~nm}{ }^{[33]}$. These porosities contains a network of rich fibrous collagen which was formed by the demineralization of dentin surface which has to be penetrated by the adhesive resin so that the final demineralized dentin structure was reinforced ${ }^{[19]}$.

The composite shrinkage causing the stresses within the material at the tooth structure interface which may be manifested as nanoleakage which in turn affect the bond at the tooth restoration interface leading to bacterial micro leakage and lead to marginal discoloration, secondary caries and pulpal inflammation and confirmed by Weinmann et al. that showed that resin composites applied in restorative dentistry exhibit volumetric shrinkage depending on the formulation and curing condition ${ }^{[34][35]}$.

Scanning Electron Microscope (SEM) was a method which was used to assess the interface between the dentin-adhesive joint and the restoration material. The accuracy of the technique depends upon the selection of a suitable dye. This dye must have the ability to be immobilized during dryness of dentin samples and also should have the ability to migrate easily through the interface zone for this reasons silver nitrate was found to be the dye of choice ${ }^{[36]}$.

Silver nitrate penetration was considered a good method for evaluation of nanoleakage due to submicron defects in resin infiltration or inadequate polymerization. However, there was controversial matter between nanoleakage and the quality of resin-dentin bonds ${ }^{[36]}$. Nanoleakage described as porosities located within and under the hybrid layer less than $50 \mathrm{~nm}$ as explained by ${ }^{[38]}$.

In the present study, nanoleakage occurs in most of etching materials used at different levels. This could be explained to the fact that most adhesives 
used in dentistry use acid etch to demineralize dentin surface and expose collagen network for the adhesive to completely infiltrate through the full thickness of the etched dentin. Nanoleakage occurs as a result of improper etching in which the etchant exposed the collagen to a depth that was difficult for the current adhesive to infiltrate and this results in a porous collagen susceptible to degradation and so the silver ions may be diffused through nanometer-sized channels that hasn't been fully infiltrated by the dental adhesive and leaving spaces for fluid penetration underneath hybrid layer ${ }^{[19]}$. Incomplete penetration of the bonding agent into the exposed collagen of demineralized dentin lead to the creation of gaps within the hybrid layer that were susceptible to degradation after that water or bacterial enzymes can infiltrate into these gaps or spaces that resulted in hydrolysis of peptides of exposed collagen that was not protected by resin or hydroxyapatite ${ }^{[17]}$.

The analysis of hybrid layer by SEM photomicrographs revealed different hybridization patterns suggesting that attachment of the interface between dentin-adhesive resin-composite resin were influenced by variety of factors and so it was impossible to make a standardization for the dentinal substrate ${ }^{[17]}$.

\section{CONCLUSIONS}

From the results of this study, it was recommended to use citric acid with low concentrations as an alternative to the commercial phosphoric acid etchant in the process of dentin etching as it has mild effect on vital dentin with improved microtensile bond strength and nanomechanical bond.

Within the limitations of this invitro study, evaluation of nanoleakage and its clinical significant was considered important procedure, further innovations of more types of adhesive systems to minimize nanoleakage in order to optimize or enhance dentin bonding should be considered in the future.

\section{REFERENCES}

1. Ayad MF: Effects of rotary instrumentation and different etchants on removal of smear layer on human dentin. J. Prosthetic Dent. 2001; 85: 67-72.

2. Pashley DH, Ciucchi B, Sano H, Horner JA: Permeability of dentin to adhesive agents. Quintessence Int. 1993; 24:618-631.

3. Tay FR, Smales RJ, Ngo H, Wei SH, Pashley DH: Effect of different conditioning protocols on adhesion of a GIC to dentin. J. Adhes. Dent. 2001; 3:153-67.

4. Nakazawa Y, Ishikawa T: Study of pulpal response to an adhesive composite restoration using NPG primer and a PMDM monomer (mirage-bond). Bull Tokoyo Dent. Coll. 1993; 34:115-134.

5. Gwinnett AJ, Kanca J III: Micromorphology of the bonded dentin interface and its relationship to bond strength. Am. J. Dent. 1992; 5: 73-77.

6. Shimada Y, Hamirattisai C, Inokoshi S, Burrow MF, Takatsu T: In vivo adhesive interface between resin and dentin. Oper. Dent. 1995; 20:204-10.

7. Ayad MF, Rosenstiel SF, Farag AM: A pilot study of lactic acid as a dentin conditioner for dentin-bonding agent development. J. Prosthet. Dent. 1996;76: 254-9.

8. Junior MM, Rocha EP, Anchieta RB, Archangelo CM, Luersen MA: Etch and rinse versus self-etching adhesives systems: Tridimensional micromechanical analysis of dentin/adhesive interface. Int. J. Adhes Adhesives 2012; 35:114-119.

9. Perdigão J, Reis A, Loguercio AD: Dentin adhesion and MMPs: a comprehensive review. J Esthet Restor Dent. 2013 Aug; 25(4):219-41. doi: 10.1111/jerd.12016. Epub 2013 Feb 19.

10. Wahyu A: Perbedaan kekuatan perlekatan tank antara resin komposit dan dentin yang diulas dengan larutan asam laktat 500/0 dan larutan asam sitrat 50\%. Surabaya: Skripsi; 2002: 2-3.

11. Strang R, Whitters CJ, Brown D, Clarke RL, Curtis RV, Hatton PV, Ireland AJ, Lloyd CH, McCabe JF, Nicholson JW, Scrimgeour SN, Setcos JC, Sherriff M, van Noort R, Watts DC, Woods D: Dental Materials: Literature Review. J. dentistry. 1998; 26 (3): 191-207.

12. Van Meerbeek B., M. Braem, P. Lambrechts, and G. Vanherle: Two-Year Clinical Evaluation of Two DentineAdhesive Systems in Cervical Lesions. J. dentistry. 1993; 21(4): 195-202. 
13. El-safty SM: Influence of varied acid concentration and varied etching time on shear bond strength of dental resincomposites. J Dent Oral Health. 2017; 9:98.

14. Van Meerbeek B, Inokoshi S, Braem M, Lambrechts P, Vanherle G: Morphological aspects of the resin-dentin interdiffusion zone with different dentin adhesive systems. J Dent Res. 1992 Aug;71(8):1530-40.

15. Perdigao J, Swift EJ: Analysis of dental adhesive systems using scanning electron microscopy. Int Dent J. 1994 Aug;44(4):349-59.

16. Walshaw PR, McComb D: SEM characterization of the resin-dentine interface produced in vivo. J Dent. 1995 Oct;23(5):281-7.

17. Macari S, Gonçalves M, Nonaka T, Santos J: Scanning electron microscopy evaluation of the interface of three adhesive systems. Braz Dent J. 2002;13(1):33-8.

18. Coppini EK, Prieto LT, Pierote JJ, Pimenta CT: Influence of enamel acid-etching on mechanical properties and nanoleakage of resin composite after aging. Brazilian J. oral sciences. 2017; 16: 17059.

19. Zhao S, Chen J, Xiong Y, Wang H: Effect of acid etching time on nanoleakage and microtensile bond strength of the adhesive-dentin bond interface. Int Chin J Dent. 2006; 6: 29-37.

20. Pashely DH: the effects of acid etching on the pulpodentin complex. Opert. Dent. 1992; 17: 229- 242.

21. Hanes PJ, O’Brien NJ, Garnick JJ: A morphologic comparison of radicular dentine following root planning and treatment with citric acid or tetracycline HCL. J. Clin. Periodontol. 1991; 18: 660- 668.

22. Van Meerbeeck B, De Munck J, Yoshida Y, Inoue S, Vargas M, Vijay P. et al: Adhesion to enamel and dentin: current status and future challenges. Oper Dent. 2003; 28 (3): 215-235.

23. Eick JD, Gwinnett AJ, Pashely DH, Robinson SJ: Current Concepts on Adhesion to Dentin. Crit. Rev. Oral Biol. Med. 1997; 8 (3): 306-335.

24. Wang Y, Spencer P: Effect of acid etching time and technique on interfacial characteristics of adhesive -dentin bond using differential staining. Eur. J. Oral Sci. 2004; 112(3):293- 299.

25. Di Lenarda R, Cadenaro M, Sbaizero O: Effectiveness of 1 mol L-1 citric acid and 15\% EDTA irrigation on smear layer removal. J. Int. Endod. 2000; 33:46-52.
26. Ozer F, Blatz MB: Self-etch and etch-and-rinse adhesive systems in clinical dentistry. Compend. Contin. Educ. Dent. 2013; 34(1):12-14.

27. Gateva N, Gusyiska A, Stanimirov P, Kabaktchieva R, Raichev I: Effect of etching time and acid concentration on micromorphological changes in dentin of both dentitions. J of IMAB 2016 Apr-Jun;22(2):1099-1110.

28. Marshall GW Jr, Inai N, Wu-Magidi IC, Balooch M, Kinney JH, Tagami J, Marshall SJ: Dentin demineralization: effects of dentin depth, $\mathrm{pH}$ and different acids. Dent Mater. 1997 Nov;13(6):338-43.

29. Nakabayashi N, Kojima K, Masuhara E: The promotion of adhesion by the infiltration of monomers into tooth substrates. J Biomed Mater Res. 1982 May;16(3):265-73.

30. Marshall GW Jr, Wu-Magidi IC, Watanabe LG, Inai N, Balooch M, Kinney JH, Marshall SJ: Effect of citric acid concentration on dentin demineralization, dehydration, and rehydration: atomic force microscopy study. J Biomed Mater Res. 1998 Dec 15;42(4):500-7.

31. Drummond JL, Racean D, Van Scoyoc J, Steinberg A: Effect of Surface Treatments on Dentin Bonding Shear Strength. Cells and Materials. 1992, 2(3):6.

32. Bagmar S, Jadhav S, Hegde V, Srilatha S: A comparative evaluation of the efficiency of different acids for removal of smear layer after cavity preparation. An in vitro study. IJRANSS. 2013 Jul; 2(1): 5-12.

33. Sano H, Yoshiyama M, Ebisu S, Burrow MF, Takatsu T, Ciucchi B, Carvalho R, Pashley DH: Comparative SEM and TEM observations of nanoleakage within the hybrid layer. Oper Dent. 1995 Jul-Aug;20(4):160-7.

34. Cara R, Fleming G, Palin W, Walmsley A, Burke F: Cuspal deflection and microleakage in premolar teeth restored with resin-based composites with and without an intermediary flowable layer. J. Dent. 2007; 35:482- 489.

35. Weinmann W, Thalacker C, Guggenberger R: Siloranes in dental composites. Dent. Mater. 2005; 21:68-74.

36. Pioch T, Staehle HJ, Duschner H, García-Godoy F: Nanoleakage at the composite-dentin interface: a review. Am J Dent. 2001 Aug;14(4):252-8.

37. Sano H, Taskstu T, Ciucchi B, Ebsiu S: Comparative SEM and TEM observations of nanoleakeage within the hybrid layer. Oper. Dent. 1995; 20: 120- 127.

38. Sano H, Takatsu T, Ciucchi B, Horner J, Matthews W, Pashley D: Nanoleakage: leakage within the hybrid layer. Oper. Dent. 1995; 20:18-25. 